\title{
Context Boards in the Teaching Foreign Languages and Philological Disciplines
}

\author{
Zayachkovskaya Ksenia $^{1^{*}} \&$ Budnik Ekaterina ${ }^{2}$ \\ ${ }^{1}$ Pushkin State Russian Language Institute \\ ${ }^{2}$ Moscow State Linguistic University
}

\begin{abstract}
Developing modern technologies in the education sector requires brand new decisions to improve the proceeding and memorise information. The accelerated study rate reduces the amount of concentration and accessible time, so an average student experiences difficulty gathering knowledge and required skills. When placed in such conditions, students and teachers find extraordinary methods for lessons and exercises to simplify acquiring knowledge and fulfilling all the tasks. The Context Board represents the specified topics and provides the ability to disclose a sufficient level of knowledge appropriately. The mentioned draft is based on different ways of memorising and popular technical capacity. The main purpose of this study is to determine the optimal method of the material presentation within the framework of the developed project. The experiments have shown the overall effectiveness of the context boards. The method itself takes into consideration the features of persons with different types of information perception. It is also essential that organising the specified and requested topics allows to systematise information and realise all the significant connections between different subjects and choose the study format.
\end{abstract}

Keywords: context board, educational technology, thematic board, memorisation techniques

\section{Introduction}

Language teaching is one of the most critical components of intercultural communication. Indeed, the formation of intercultural competencies is one of the critical goals in teaching various languages. Since the development of technologies of education requires new solutions for processing and storing information, it is fair to say about the need to create innovative ways and methods of teaching the liberal arts related to languages (that is, linguistics) and linguistic and cultural studies in general. Teachers of foreign languages and disciplines related to regional studies, often suffer from the fact that progress is faster than the development of the educational standards (Karpov, 2010, p.80).

A simplified understanding of meanings leads to the superficiality of knowledge and an inability to apply it in practice. The accelerated pace of learning reduces long-term memory usage: often a student who did not have time to master something in a short time, forever loses the opportunity to master this knowledge. In these circumstances, students and teachers should be able to apply various interactive solutions for their classes, which help them perceive and assimilate information more deeply and better. The situation is complicated by the various difficulties students experience when getting acquainted with Russian culture in studying the Russian language.

However, CB can also be useful when studying the history of a language, as they can show the features of the expression and content plans of various linguistic units. Also, the CB demonstrated its effectiveness during the classes on the history of art, literature and philosophy. It is assumed that CB may also be relevant for the study of other humanities and arts.

The Context Board (CB) is a multifunctional thematic space project that allows you to record, organise, and remember information in the most user-friendly way. Development is based on various memorisation techniques and available technological capabilities. Experiments in the classroom have proven the effectiveness of CB. It is 
also important to note that the $\mathrm{CB}$ method pays attention to students' characteristics with different types of information perception. Organisation of thematic space helps organise information better, teaches students to see interdisciplinary connections, and helps to choose a convenient format for memorisation.

One of the main difficulties that international students face when learning Russian is the cultural barrier. It means the impossibility without special knowledge to understand a culture that is not native to oneself, considering the concepts and archetypes established in it. This factor can significantly slow down the language learning process. Therefore, the main idea of CB is aimed at leveling mental and psychological difficulties in learning. Furthermore, that is why a competent pedagogue should regulate part of CB's work to help the student in difficult issues.

First of all, CB is a linguistic and cultural tool that visually gets acquainted with the language and culture and complements any textbook. This technology can be useful in the media century since it is a model of the inconsistent information field.

\section{Literature review}

In humanitarian knowledge, there is an active development of new ways of interpreting and communicating information. This work is based on the works of Russian and foreign scholars of humanitarian learning. First, turn to the card system used to memorise new information. These can be flashcards with new words, rules, terms, definitions, etc. Our time's technical capabilities make it possible to create and organise virtual flashcards; for this, there are also special applications. The familiar flashcard memory systems are based on the work of Sebastian Leitner and Paul Pimsler who based their method on the «spaced repetition method», in the process of using which the studied material is sorted according to the degree of digestibility (see So lernt man Lernen (How to teach to learn).

However, the inclusion of such cards in the learning process can be viewed a little more broadly. For example, students can fill whiteboards with cards based on the knowledge gained in lectures and lessons while doing homework and preparing for seminars.

Such cards are one of the fundamental methods of submitting the necessary material to the CB.

Another exciting information processing technology that inspired the creation of CB is a mind map. A mind map is a way of structuring and organising information in one coherent diagram. Mind maps and their elements can become part of the context board if required for a creator.

In the CB's case, the formulation of Joseph Novak was the starting point for developing the idea of the research. Initially, the $\mathrm{CB}$ was conceived as a detailed version of the intelligence-map, and, then, in following-up revision, it gained the potential to find its methodological solutions.

The most crucial element of CB formation is the concept map (or conceptual diagram). A concept map is a unique chart that expresses the connections between different concepts. Joseph D. Novak introduced this concept. He developed concept maps as a way to provide new information to students. The principle of his teachings based on the phased application of new knowledge to the existing ones at his disciples. Such cards are often used in various activities, including methods of teaching foreign languages. Concept maps can solve logical problems, pose new questions, transform research activities, and much more.

However, during this project's development, attention was also drawn to some modern articles summarising previous studies' experience. We want to acknowledge Dr. Melinda Dooly «Empowering Language Minorities through Technology: Which Way to Go? Which Way to Go?». The article conducts a multifaceted study of possible ways to achieve social equality through education through modern technologies' prism. The analysis is 
carried out on the example of a representative social group - representatives of minority linguistic communities in the European Union. The author gives ways of implementing TEL (Technologically Enhanced Learning), analyses possible risks, and emphasises TEL's importance for drawing public attention to education problems in minority languages (Dooly, 2010).

Another critical study in this article is Olimpius Istrate's «Visual and pedagogical design of eLearning content». In this article, the author highlights essential visual and methodological principles for developing educational materials in a digital environment, focusing on content design issues. The author analyses specific procedural decisions of pedagogical design in their direct connection with the goals of learning. The author outlines the main ideas of pedagogical design necessary for the further implementation and improvement of eLearning (Istrate, 2009).

One of the essential purposes of CB's use in the educational process is the desire to democratise the learning process and its orientation to the comfort of a student and a teacher. As an example of modern technologies in education, CB can help reduce the oppressive intellectual and psychological distance between the teacher and the student. The CB aims to reduce the potential psycho-emotional trauma of the educational process associated with difficulties with the perception of educational materials.

\section{Methods}

When developing this technique, we used the following research methods: analysis of existing methods of memorising and teaching humanitarian disciplines, including foreign languages; experiment (CB was tested on schoolchildren of primary and secondary school age (8-12 years old), as well as on students of higher educational institutions.

In general, the work on the study was carried out in the format of project activities. Thus, a unique plan was formed, within the framework of which the observations and experiments were carried out. The main criteria for its success were the following elements:

1. Audience involvement in the learning process from $70 \%$;

2. Maintaining communication between the teacher and the students during the entire class (120 minutes);

3. Reproducibility of the lesson material by the audience over time.

For this purpose, we used different variations of similar practices - that is, some forms of working with electronic cards and the interactive board in conditions of working with a prepared scheme, or in real-time within the framework of seminars, the format of which allows to add new elements to the classical curriculum.

An essential element of the study was a survey of the students who listened to classes using CB and received homework on the boards presented during the lessons.

Then, a comparison of academic performance was made on the topics covered by the classical plan and the topics that were analysed using a contextual board. In general, the Faculty of Pre-University Education students who were studying Russian as a foreign language showed a $15 \%$ higher academic performance in the History of Russian Literature program when they were introduced to the CB. Also, the new format of presentation stimulated students' interest in the subject during classes.

It creates the descriptions and notes, searching for the meanings of the words and terminological meanings and comprehending them, selecting the thematic images, videos, excerpts from the national literature, song, etc. that can be understood. They expand linguistic and cultural horizons; meanwhile, the independent search for 
information and its adaptation to a unique type of perception contributes to memorising them. As a result, we get a thematic field formed from information cards that resemble a puzzle. Each card becomes an important fragment in the disclosure of the overall theme.

The main goal of the project research is to create methodological algorithms for delivering educational material in the framework of teaching philological disciplines to the audience using CB.

However, the accentuation of the method on the systematisation of heterogeneous elements to obtain a whole picture is not entirely exhaustive. When working with a foreign language, the $\mathrm{CB}$ offers a unique algorithm for deploying the linguistic material in context. By saying context, we will see not only the academic base of texts in the language's corpus. We expand the concept of context: this is both the immersion of the sign-in cultural realities and its deployment in retrospect (up to the search for common historical roots with their mental component).

Mastering the concept sphere of the studied language is very important in the learning process. Identifying and understanding concepts in a language is the key to understanding culture's features expressed through the language. This skill is the main one in the development of cross-cultural competence. Simultaneously, working with concepts should be immersed in the simulated communication situation, because ultimately, the primary goal of language learning is the ability to apply knowledge in practice (Passov, 1989, p.150). The synthesis of various methodological components in students ' grammatical skills leads to faster learning and easier understanding of the material (Porechenkova, 2015, p.22-23).

A contextual board can come in handy.

\section{Results}

It is necessary to answer the following question: what key concepts does the CB include? They can be summarised in three components of the suggested learning principle:

- The work is carried out on any material;

- Language and culture are each other's creators and donors, so they cannot be separated in the learning process and must be mastered in parallel;

- Learning a language is a journey into the culture of the nation that speaks it.

- Principally, there are two main models for working with $\mathrm{CB}$ :

- Deep research work with lexical units (for the $\mathrm{C} 1 / \mathrm{C} 2$ level and native speakers);

- Building up an introductory board with audio-visual material.

Each format assumes unique algorithms for working with lexemes (and paradigmatic forms of the words) and its organisation of the information space. These models can be formally described as an «advanced level» with the scientific deployment of the semantic fields, lexical-semantic groups, etc. Thus, this «advanced level» is an exclusively linguistic work. The «basic level» involves the creation of introductory training material. It is formed based on various available facts about any phenomena of the world reflected in the language. In order to avoid difficulties and confusion, we will give some brief definitions of the necessary concepts.

A semantic field (SF) is a semantic paradigm whose units are grouped around a lexeme that expresses an ordinary meaning. A lexeme that expresses a shared meaning is called an archiseme. The SF may include different parts of speech and different types of their relationships. In general, the SF can be represented as a sphere with a core (this will be the archiseme) and its surrounding elements - different classes of values. Different SF intersects and overlaps with each other (Kuznetsov, 1998, p.380) (Jackson, 2000, p.14). 


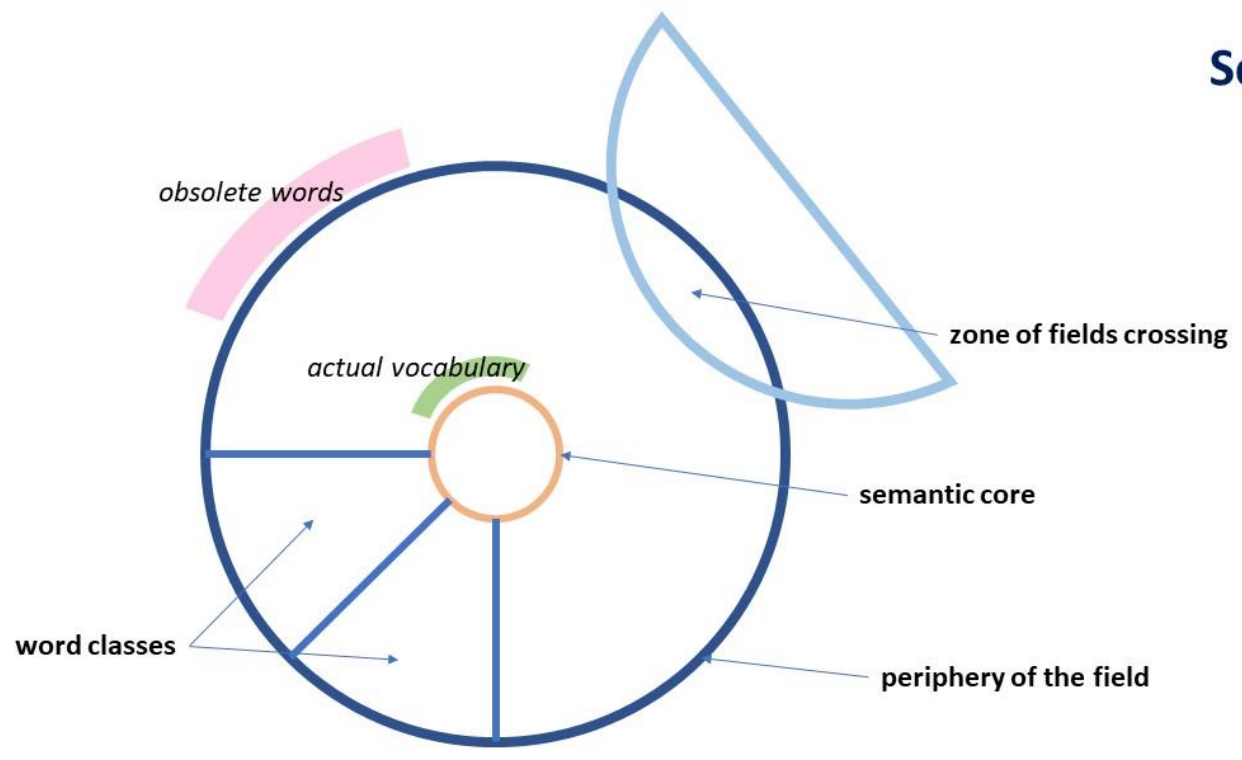

\section{Semantic field}

Figure 1. A scheme of semantic field

Lexical-semantic group (LSG) / lexical field / is a group of words of one part of speech, united by an ordinary meaning (Akhmanova, 1966, p.207-208).

A lexical-semantic variant (LSV) is a compound word that can be included in different micro fields and SF (Akhmanova, 1966, p.207-208).

Despite the long-standing publication of the materials that this layer of research is based on, the stated provisions are relevant due to their development in Russian grammar.

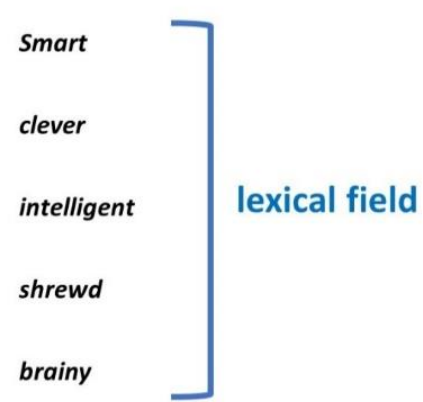

Figure 2. An example of the lexical field

What is the «advanced level»? The format of in-depth research involves creating a three-level scheme for working with different lexical units of the SF, which consists of:

1. The Central unit (core), around which the work is built, is being determined. It is also necessary to conduct the morphemic and morphological analysis (if necessary), determining the selected values morphemes.

2. Then, an etymological analysis is being conducted. This unit's origin is determined, if possible, the ancient root is selected, and translations into other foreign languages (Indo-European family of languages) are added. 
The purpose of this activity is to obtain a representation of the historical formation of the lexical item and the likelihood of some of his original mental components.

3. Further, it is possible to draw up the necessary SF, LF, define the concept's scope, identify the system connections, and so on.

Such a detailed work can be useful in preparing an analysis of the concept sphere of significant concepts («любовь» («love»), «хлеб» («bread»), «смерть» («death»), «земля» («earth»), etc.)

It is important to note that the information supported by visual components leaves a more considerable amount of related information in the student's memory (Madigan, Rouse, 1974, p.151-158), (Krotova, 2008, p.165).

We offer an example of this scheme using the word «небо» («sky»):

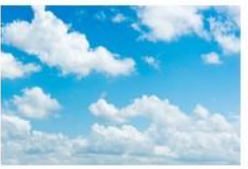

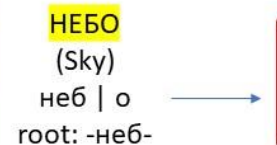

root: -неб-

/noun, inanimate, neuter/
Обозримое воздушное пространство над землей

/the atmosphere above a given point, especially as visible from the ground during the day/

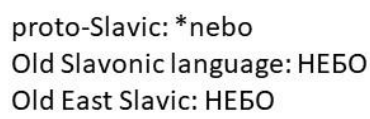

口 небо- понятие, имеющее положительную окраску. это понятие со знаком «+». Ассоциативно-связанная лексика: Твердь, купол, свод, небосвод, небеса

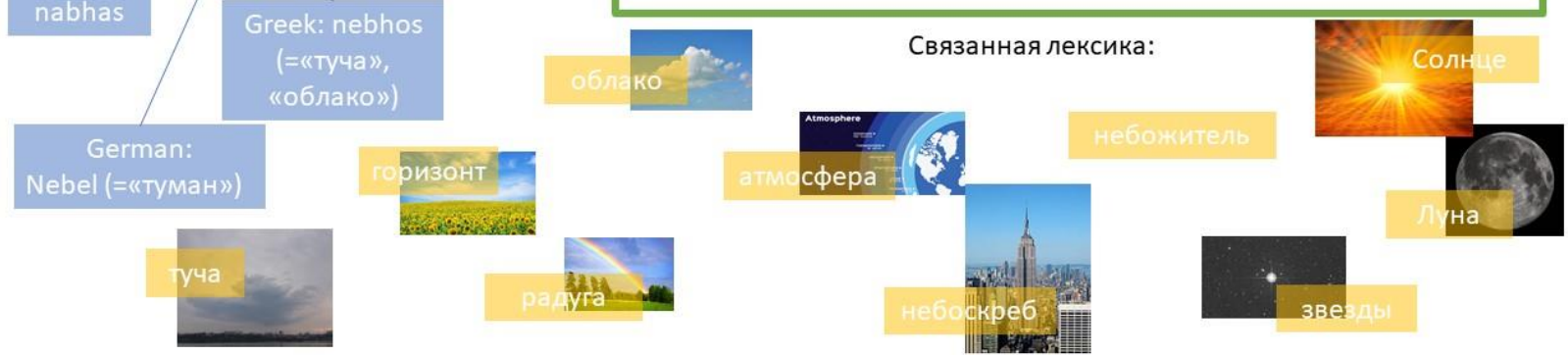

Figure 3. An example of a CB with the word "sky"

To consider the basic principle of a CB operation, we will look at the concept of the word «business», for example. Let us consider its mental component in the Russian language from the conceptualisation of human activity's economic field. The word «business» in Russian is borrowed, so it will be easy to memorise. However, we can highlight some features of Russian-speaking people's attitude to this concept and choose some nonborrowed synonyms. So what we get:

A list of additional vocabulary related to different areas of business (including national): договор, сделка, делец, фирмач еtс.;

Highlighted features of the mental perception of the business sphere (business is often likened to the animal world: «business sharks»);

A group of phraseological units related to business: «иметь свое дело» (to have your own business), «акулы бизнеса» (business sharks), «акционерное общество» (joint-stock company), «слияние и поглощение капиталов» (mergers and acquisitions, M\&A) etc. (Babenko, 2010, p.267-272) 
Thus, we have already gained a relatively extensive understanding of such a phenomenon of Russian culture as a business, within the framework of one (!) Thematic space. However, the Context Board allows to expand this view too. Within the framework of the concept of «business», the topic of the history of Russian entrepreneurship can be extensively touched upon, the skills of business writing in Russian can be improved, and a whole module can be distinguished with the national characteristics of business communication in the Russian-speaking environment (the formation of concepts about business hierarchy, time relations, communication norms, etc.). In turn, such concepts of concepts can be combined into even larger fields (for example, how the concept of «business» is included in the concept of «economics», and this is a part of representation in the language of human activity) (Krass, 2009, p.97-117).

Working with lexemes in this way, we get a whole modular system that allows us to cover many thematic materials in a single information space. Besides, active work with full-fledged texts contributes to developing an important competence - mastering grammatical skills, which are the fundamental basis of any language (Ryabtseva, 2010, p.22-24).

As part of the development of the methodology, CB was used in interactive lessons in foreign history for native schoolchildren. Children of 8-12 years old, the lecture on the topic «Culture of Ancient Greece» was offered for familiarisation through the game with multimedia accompaniment. For this, we created a thematic interactive field with a set of culturally significant concepts of ancient Greek life. Gaming activity led to the maximum involvement of schoolchildren in the work process. A month later, the children were able to recall about $60 \%$ of the lecture material during the survey.

When working with international students studying Russian as a foreign language, a similar interactive engagement method was used. We conducted the lesson on the topic «The period of the reign of Ivan IV the Terrible» as a part of medieval Russian literature. To conduct an introductory historical lesson, we decided to abandon the usual reading of information filled with complex factual material. This decision was made in connection with the problematic assimilation of the national history events by the students who are not engraved in the Russian-speaking environment. Instead, the audience was offered linguistic and cultural material focusing on key concepts and events with their detailed explanation (the etymology of the word «tsar»; the concept of «Moscow, third Rome», «the oprichnina», etc.). Subsequently, teachers of literature noted an increased interest in works from the correspondence of Ivan the Terrible and a better understanding of the content for $35 \%$ than before.

Thus, we can conclude that the introduction of the CB methodology into a conservative learning process even in individual lessons can increase the educational process's effectiveness.

\section{Discussion}

Flexibility in the use of various platforms allows using $\mathrm{CB}$ on any gadget or platform. Teachers can work on the whiteboard in programs such as Miro (https://miro.com) or Microsoft PowerPoint. If it is not possible to use a gadget, diagrams can be created on paper, and later converted into digital format, supplemented with multimedia.

The method of such teaching is the emphasis on the active involvement of students in the educational process. This is how the notion that independently «obtained» knowledge is more firmly fixed in memory is realised. Boards with cards formed based on the «core of words» can be supplemented with information of any format. When working with the material under study, different memorisation techniques are used, and the ability to build associative links helps to master the information. Thus, involuntary memorisation, which may have more potential than purposeful memorisation, is activated. (Zinchenko, 1961, p.472), (Fetisova, 2009, p.25). 
So, CB can open up new opportunities both in face-to-face work with an audience and in self-preparation. Boards can be drawn up according to the discipline's current work program or as part of the textbook program. Perhaps the teacher wants to make a board on a specific topic: the possibilities for pedagogical creativity and the use of various materials are practically unlimited. In this case, the creation of cards can be individual or collective work. It is essential to understand that working through the cards' material is an obligatory part of the training.

The CB format solves the problems of memorising new vocabulary, its implementation (i.e. application in practice), and the introduction of new terms related to various aspects of the country's culture with which students get acquainted in the classroom. Simultaneously, it is possible to create comfortable conditions for students with different types of information perception. A comprehensive educational material presentation with images, videos, audio tracks and adapted texts will make learning comfortable for audiences, visuals, kinesthetics, and students with a dominant discrete representational system. Linguistic students who study a language at a scientific level can use a system of three zones: determining the historical roots and mental base, creating lexical-semantic fields, and selecting an explanatory context.

Thus, CB allows non-native speakers to understand better the mental components of the target language. This is a very important component of the curriculum devoted to a foreign language, since the concept sphere is the sphere of the most visual representations of the semantic structures of the language (Pankina, 2004).

When it comes to teaching non-Slavic languages to a Slavic audience, CB can also be useful. For example, within the framework of working with an audience in which Russian is taught as a non-Slavonic one, a teacher can use a trick with words that are consonant and similar in meaning, or vice versa - words that have a similar or identical sound and spelling, but at the same time have antonymic meanings.

In conclusion, we will note that the use of cards in $\mathrm{CB}$ helps increase learning effectiveness, making the educational process more comfortable for each student and personalised.

So, we can say that contextual boards make information more accessible by using a large amount of visual material and interactive solutions. The CB can help to visualise the material being studied and disassemble it into components of different levels, which means that the research subject can be considered almost comprehensively.

However, such technology as the CB requires creating a unique methodology for integration into the educational process. The main difficulty lies in developing special instructions and teaching methods that will allow the use of $\mathrm{CB}$ in the educational process without compromising the tasks of the curriculum and without the risk of exceeding the number of seminar hours.

The CB's use also requires the student to spend much time selecting and comparing thematic information. The $\mathrm{CB}$ is an element of a fundamental approach to education. It is aimed at the compilation and production of its conclusions based on the processed sources. Moreover, this fact requires recognition that the $\mathrm{CB}$ cannot be convenient for all categories of students. The use of CB technology is optional.

However, in the subsequent revision and correction, the CB can become a promising alternative to the classical methods of working with the audience studying the humanities and arts, in particular philological disciplines.

\section{References}

Akhmanova, O. (1966) Dictionary of linguistic terms. Moscow. Soviet encyclopedia. p. 597 
Babenko, L. (2010). The concept of the Russian language: key concepts and their representations, based on vocabulary, phraseology and paremiology. Dictionary prospectus. Yekaterinburg: Ural University Publishing House, 338 p.

Budnik, E., Kuvaeva, A., Leshutina I., Naumenko Yu., Vokhmina L. (2020). Enhancing and impacting of the infographics potential as a part of directed activities related to multicode texts. 14th International scientific conference "Society. Integration. Education" 22-23 May. Rezekne, Latvia

Crassus, N. (2009). Russian language and culture of speech. Materials for practical exercises: Textbook for students of higher educational institutions. - Moscow. TEZAURUS. p. 97-117.

Dooly, M. (2010). Empowering Language Minorities through Technology: Which Way to Go?. Faculty of Education, Universitat Autònoma de Barcelona, eLearning Papers, 19, pp. 1-12

Fetisova A. (2009, January). Methodological Possibilities of Using Involuntary Memorization in Teaching Vocabulary. Vestn. Moscow un-that. Linguistics and intercultural communication. p.23-29.

Foer, D. (2013). Einstein Walking on the Moon: The Science and Art of Memorization. Moscow. Alpina Publisher. p. 270.

Jackson, H., \& Etienne Zé Amvela (2000). Words, Meaning, and Vocabulary, Continuum, p14.

Karpov, A. (2010, June). Educational epistemology and knowledge transformation». Vestn. iskcon. un-ta. Philosophy. p. 79-92.

Krotova, I., \& Kamoza, T., et al. (2008, April). The method of visualization in the system of innovative education. Higher education in Russia. p. 164-167

Kuznetsov, A. (1998). Field. Big Encyclopedic Dictionary. Linguistics. Moscow. Great Russian Encyclopedia. p. 380 .

Leitner Sebastian. (2019). Spaced repetition method (From the book «How to learn to learn»). - M .: Publishing house "Pero". p. 106.

Madigan, S., \& Rouse, M. (1974, March-June). Picture memory and visual generation processes. The American Journal of Psychology. Vol. 87. pp. 151-158.

Osipovskaya, E., Dmitrieva S., Barabash V., Budnik, E. (2019). Cutting edge online presentation software in higher education. 12th annual International Conference of Education, Research and Innovation Seville, Spain. 11-13 November. ISBN: 978-84-09-14755-7 / ISSN: 2340-1095 doi: 10.21125/iceri.2019

Pankina M.F. $(2004,1)$ The semantic space of a language and approaches to its study. Cognitive linguistics issues. p.146-149

Passov, E. (1989). Fundamentals of communicative methods of teaching foreign language communication. Moscow.

Persikova, T. (2017). Development of intercultural competence as one of the tasks of teaching a foreign language. Language. Culture. Society. Actual problems, research methods and teaching problems. Collection of articles. - Moscow. Publishing and trade corporation «Dashkov and K 182 p. - p. 120-135.

Polyakova, Yu. (2008, August). Russian as a foreign language: problems of assimilation. Moscow Higher education in Russia. p. 153-155.

Porechenkova, E., \& Kazantseva, S. (2015). Formation of grammatical skills of speech based on the communicative methodology of teaching a foreign language in a non-linguistic university. Practice of teaching foreign languages in the system of continuous education. Linguistics and intercultural communication. Moscow. Vestnik Moskovskogo universiteta. 19 (1).

Ryabtseva, O. (2010). Formation of the grammatical component of foreign language communicative competence. Izv. Southern Federal University. Technical science. Taganrog. T. 111 (10), p. 116.

Zinchenko, P. (1961). Involuntary memorization. Moscow. 